九州大学学術情報リポジトリ

Kyushu University Institutional Repository

\title{
Comparative Study of Bare and Emulsified Nanoscale Zero-valent Iron for Nitrate and Phosphorus Removal
}

\section{El jamal, Ramadan}

Department of Earth System Science and Technology, Interdisciplinary Graduate School of Engineering Sciences, Kyushu University

\section{Maamoun, Ibrahim}

Department of Earth System Science and Technology, Interdisciplinary Graduate School of Engineering Sciences, Kyushu University

Sugihara, Yuji

Department of Earth System Science and Technology, Interdisciplinary Graduate School of Engineering Sciences, Kyushu University

Eljamal, Osama

Department of Earth System Science and Technology, Interdisciplinary Graduate School of Engineering Sciences, Kyushu University

https://doi.org/10.5109/4102487

出版情報: Proceedings of International Exchange and Innovation Conference on Engineering \& Sciences (IEICES). 6, pp. 192-197, 2020-10-22. Interdisciplinary Graduate School of Engineering Sciences, Kyushu University バージョン：

権利関係 : 


\title{
Comparative Study of Bare and Emulsified Nanoscale Zero-valent Iron for Nitrate and Phosphorus Removal
}

\author{
Ramadan Eljamal, Ibrahim Maamoun, Yuji Sugihara, Osama Eljamal* \\ Department of Earth System Science and Technology, Interdisciplinary Graduate School of Engineering Science, \\ Kyushu University, Fukuoka, Japan \\ *Corresponding author email: osama-eljamal@kyudai.jp
}

\begin{abstract}
This work aims to demonstrate the effect of polyethylene sorbitan monolaurate (PSM) on the properties and reactivity of nanoscale zero-valent iron (nZVI). PSM was used in this work to prepare an emulsified nZVI to overcome the particle aggregation phenomenon of $n Z V I$ and show the prepared particles with good properties. For that purpose, TEM, XRD and reactivity test of nitrate and phosphorus were performed to show the changes in the performance of $n Z V I$ after being emulsified with PSM. The results showed that the emulsified (PSM) greatly improved the removal efficiency of nitrate. Moreover, PSM enhanced the particle dispersion of nZVI and showed the particles with good properties. The results showed that the emulsified nZVI with PSM was also suitable for reduction of nitrate even at a wide range of pH. This study proposed that the emulsified nZVI could have a significant contribution in the aspects of water treatment only for the reducible contaminates.
\end{abstract}

Keywords: Nitrate; phosphorus; nanoscale zero valent iron; emulsified-nZVI

\section{INTRODUCTION}

Wastewater is known as water that has been affected negatively in quality by the generated pollutants from domestic use, agricultural and industrial activities [1]. Nutrient elements of nitrate and phosphorus are among the most found elements in wastewater [2]. Exceeding the concentration of nutrient elements in wastewater to more than the acceptable levels could adversely affect human health and the environment [3]. Therefore, several efforts have been made to increase water quality by removing the undesired elements such as nitrate and phosphorus. Among these efforts, marble dust [2], aluminum oxide particles [4], and bimetallic nanoparticles [5] were used as sorbents for phosphorus. Additionally, surfactant-modified zeolites [6], carbon nanotube [7], and chitosan nanofibers [8] were among the most used nanomaterials for nitrate removal. Owing to its strong reducing power and high adsorption capacity, nanoscale zero-valent iron (nZVI) was used for nitrate and phosphorus removal [9]. Nevertheless, due to the strong magnetic attraction of nZVI, this approach is also in need of improvement to overcome the aggregation phenomenon. Therefore, the objective of this study was to impregnate nZVI with polyethylene sorbitan monolaurate (PSM) as a good emulsifier by following the pre-agglomeration approach of synthesis. Impregnation of nZVI with PSM could have a significant contribution to offer nZVI particles with good properties and to provide a suitable reactivity toward the target contaminants

\section{MATERIALS \& METHODS}

\subsection{Synthesis of bare and emulsified nZVI}

nZVI was prepared by following the chemical reduction reaction according to the following chemical equation.

$$
\begin{aligned}
& 2 \mathrm{FeCl}_{3} \cdot 6 \mathrm{H}_{2} \mathrm{O}+ 6 \mathrm{NaBH}_{4}+18 \mathrm{H}_{2} \mathrm{O} \longrightarrow \\
& 2 \mathrm{Fe}^{0}+21 \mathrm{H}_{2}+6 \mathrm{~B}(\mathrm{OH})_{3}+6 \mathrm{NaCl}
\end{aligned}
$$

In detail, to prepare $1 \mathrm{~g}$ of nZVI, $2.2 \mathrm{~g}$ of sodium borohydride was dissolved in $100 \mathrm{~mL}$ deoxygenated deionized water which was pumped with a flow rate of

$20 \mathrm{~mL} / \mathrm{min}$ into $500 \mathrm{~mL}$ four-neck open flask containing $5 \mathrm{~g}$ ferric chloride dissolved in $200 \mathrm{~mL}$ deoxygenated deionized water and the synthesis temperature was set at $30{ }^{\circ} \mathrm{C}$. Once all $\mathrm{NaBH}_{4}$ solution was added, the mixture was stirred for an additional $5 \mathrm{~min}$ as an aging time. Afterward, the produced particles were collected and dried using vacuum-filter [10]. For preparing an emulsified PSM-nZVI, the ferric chloride was mixed for 30 min with different concentration of PSM varied between 0.2 to $2 \mathrm{~g} / \mathrm{L}$.

\subsection{Characterization of bare and PSM-nZVI}

In this work, transmission electron microscopy (TEM, JEM-ARM 200 F, JEOL Co., Japan) was used to examine the surface morphology and particle size for bare and PSM-nZVI. From TEM images and using ImageJ program, the size and size distribution of nZVI before and after being stabilized were calculated. Moreover, Xray diffraction analysis (XRD, TTR, Rigaku, Tokyo, Japan) was performed to investigate the crystalline and amorphous structure of nZVI before and after being stabilized with PSM.

\subsection{Assessment of bare and PSM-nZVI reactivity}

Batch experiments were performed to evaluate the effect of PSM addition on the efficiency of nZVI. These experiments were executed in $300 \mathrm{ml}$ conical flask using $300 \mathrm{mg} / \mathrm{L}$ and $100 \mathrm{mg} / \mathrm{L}$ of nitrate and phosphorus solution respectively with adding $0.25 \mathrm{~g}$ of bare and/or stabilized PSM-nZVI. Before adding nZVI or PSMnZVI, nitrate and phosphorus solution were purged with nitrogen bubbles for $10 \mathrm{~min} .2 \mathrm{ml}$ of solution sample was taken at specific time intervals. Afterward, samples were filtered using $0.22 \mu \mathrm{m}$ membrane to be analyzed for nitrate and phosphorus concentration using a spectrophotometer device. The maximum nitrate and phosphorus uptake capacity of bare and emulsified nZVI was calculated by the following equation [11]. 
$q_{t}=\left(\mathrm{V}\left(C_{0}-C_{e}\right)\right) / \mathrm{m}$

Where, $\mathrm{q}_{\mathrm{t}}(\mathrm{mg} / \mathrm{g})$ is the maximum uptake capacity at a specific time; $\mathrm{V}$ is the volume of the solution; $\mathrm{C}_{0}$ and $\mathrm{C}_{\mathrm{e}}$
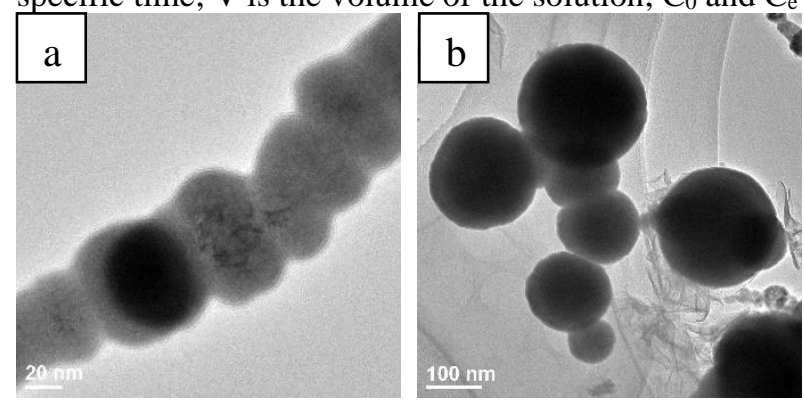

Fig. 1. TEM images of bare-nZVI (a), and stabilized PSM-nZVI particles (b).
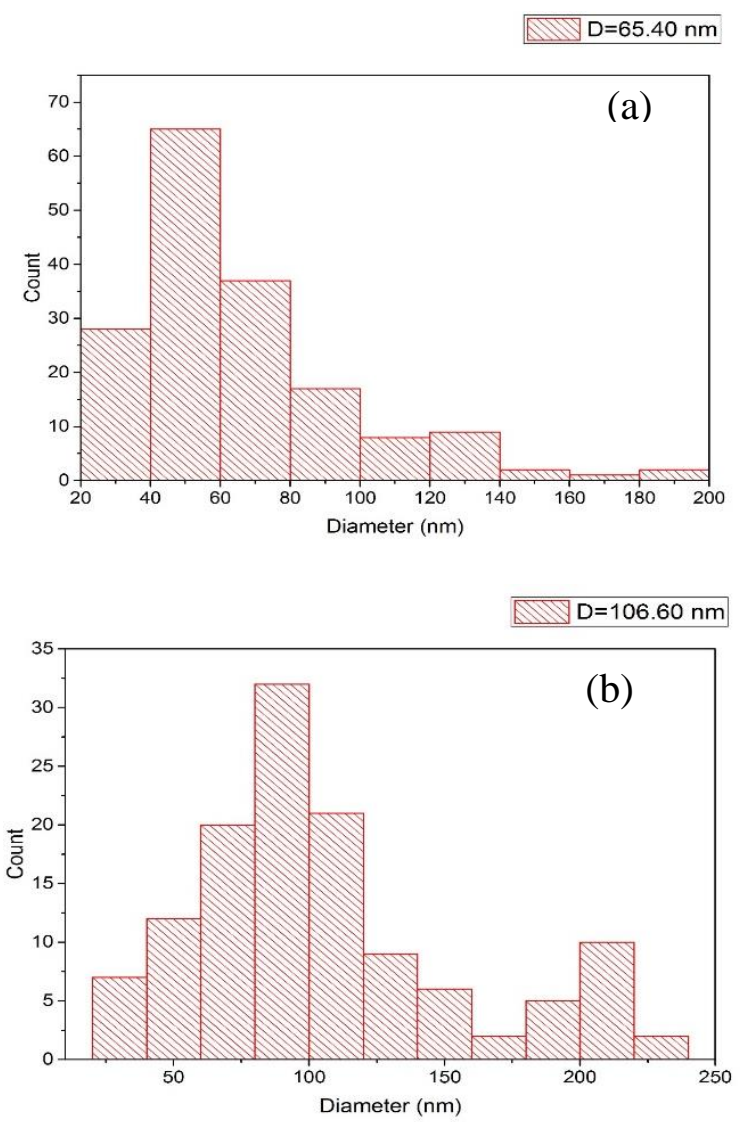

Fig. 2. Average particle size and size distribution; (a) bare-nZVI, and (b) stabilized PSM-nZVI.

$(\mathrm{mg} / \mathrm{L})$ are the initial and final concentrations of nitrate and phosphorus; $\mathrm{m}(\mathrm{g})$ is the mass of adsorbent. In order to investigate the effect of $\mathrm{pH}$, the very same experimental conditions were used with only changing the initial $\mathrm{pH}$ value of nitrate and phosphorus which was ranged between 3 to 12 .

\section{RESULTS \& DISCUSSION}

\subsection{Characterization}

TEM analysis investigated the morphologies of bare and PSM-nZVI, and the images are presented in Fig.1. The image of bare nZVI confirmed its necklace-like structure and the particles were mostly aggregated. On the other hand, TEM image of PSM-nZVI shows the particles separated with a clear core-shell structure which could prove the ability of PSM to prevent particle aggregation. Moreover, the dark color of PSM-nZVI indicates heavier atomic mass, whereas the grey color of bare nZVI particles indicates lighter atomic mass, illustrating the reason behind the improved reactivity toward nitrate and phosphorus removal using PSM-nZVI.
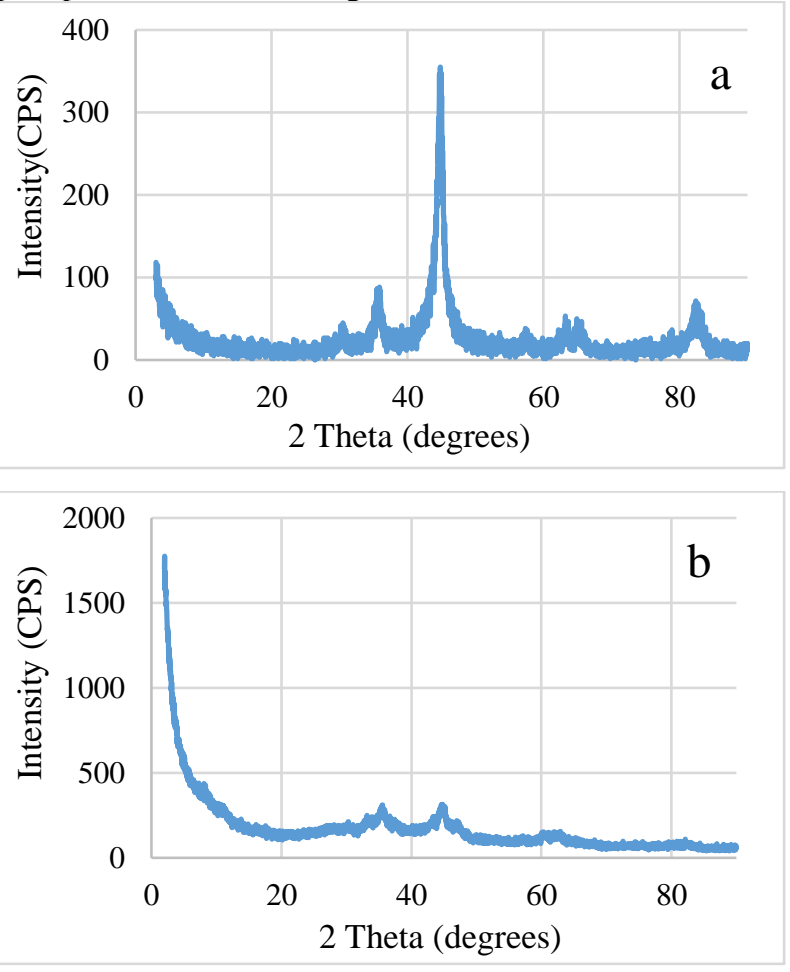

Fig. 3. XRD patterns of nZVI; (a) bare-nZVI, (b) PSMnZVI.

It was noticed that the nZVI particles were wrapped with the emulsifier which resulted in creating a shell layer on the surface of nZVI particles. The emulsifier's shell layer worked as barriers around the particles to decrease their magnetic attraction, thereby, preventing particle aggregation. In spite of producing distributed and separated particles with using the emulsifier, the particle size of nZVI was not decreased. Also, it was noticed that the particle size of nZVI after being stabilized with the emulsifier was slightly increased which could be attributed to the shell layer of the emulsifier. As it presented in Fig. 2, the average particle size and size distribution were larger after the emulsification of nZVI. In order to investigate the crystallinity, chemical composition and the emulsifier's adsorption on the surface of nZVI, XRD was performed before and after the emulsification of nZVI. Fig.3 a shows XRD pattern of bare-nZVI which demonstrates the formation of zero valent iron with very sharp peaks at $2 \theta$ of 44.6and 82.4. These results confirmed the crystallinity and purity of the synthesized iron nanoparticles. In contrast, when the nZVI particles were emulsified, the crystalline structure was completely changed to amorphous with a large decrease in the peaks of zero valent iron as shown in Fig. 3 b. The amorphous structure alongside with the new formed compounds such as $\mathrm{FeC}$ and $\mathrm{FeCO}_{3}$, confirmed that the emulsifier was well bounded and adsorbed on the surface of nZVI. The XRD pattern of nZVI was dramatically changed to amorphous after being emulsified. The amorphous structure of the emulsified nZVI is due to disrupting the periodic arrangement of atoms which leads to reflecting the $\mathrm{X}$-ray in many directions and obtaining the amorphous structure. These results confirmed that the emulsified nZVI was successfully synthesized through the formed bonds 
between the atoms such as $\mathrm{CFe}_{3}$ and $\mathrm{Fe}_{3} \mathrm{O}_{4}$, implying that the adsorption mechanism of the emulsifier on the surface of nZVI was through the chemical bonds.

\subsection{Nitrate removal using bare and PSM-nZVI}

Nitrate removal was investigated using bare and PSMnZVI. Several experiments were carried out with different loads of PSM $(0.2,0.4,0.6,1$ and $2 \mathrm{~g} / \mathrm{L})$ to $\mathrm{nZVI}$ to detect its effect on the reactivity of nZVI towards nitrate reduction. As shown in Fig. 4 a, nitrate reduction improved largely with increasing the PSM concentration up to $0.6 \mathrm{~g} / \mathrm{L}$. However, high PSM concentrations more than $0.6 \mathrm{~g} / \mathrm{L}$ negatively affected nitrate reduction. Therefore, a dosage of $0.6 \mathrm{~g} / \mathrm{L}$ of PSM was the optimum concentration for emulsifying nZVI. The maximum nitrate uptake capacity calculated using eq. 2 showed that the maximum uptake capacity of nitrate using bare nZVI reached $133.6 \mathrm{mg} \mathrm{NO}_{3} / \mathrm{g} \mathrm{nZVI}$, whereas, the maximum uptake capacity of nitrate using PSM-nZVI at the optimum concentration of PSM to nZVI (0.6 g/L) reached $233.04 \mathrm{mg} \mathrm{NO}_{3} / \mathrm{g}$ PSM-nZVI. The improvement of nitrate reduction could be attributed to the lower agglomeration of PSM-nZVI particles as it was observed from the obtained TEM images. The separated and particles of nZVI after being emulsified with PSM resulted in increasing the reaction rate of nitrate reduction due to the increased number of the released electrons from the core of nZVI. Therefore, the emulsifier of PSM is highly recommended to be used for synthesizing dispersed nZVI particles for efficient nitrate removal.

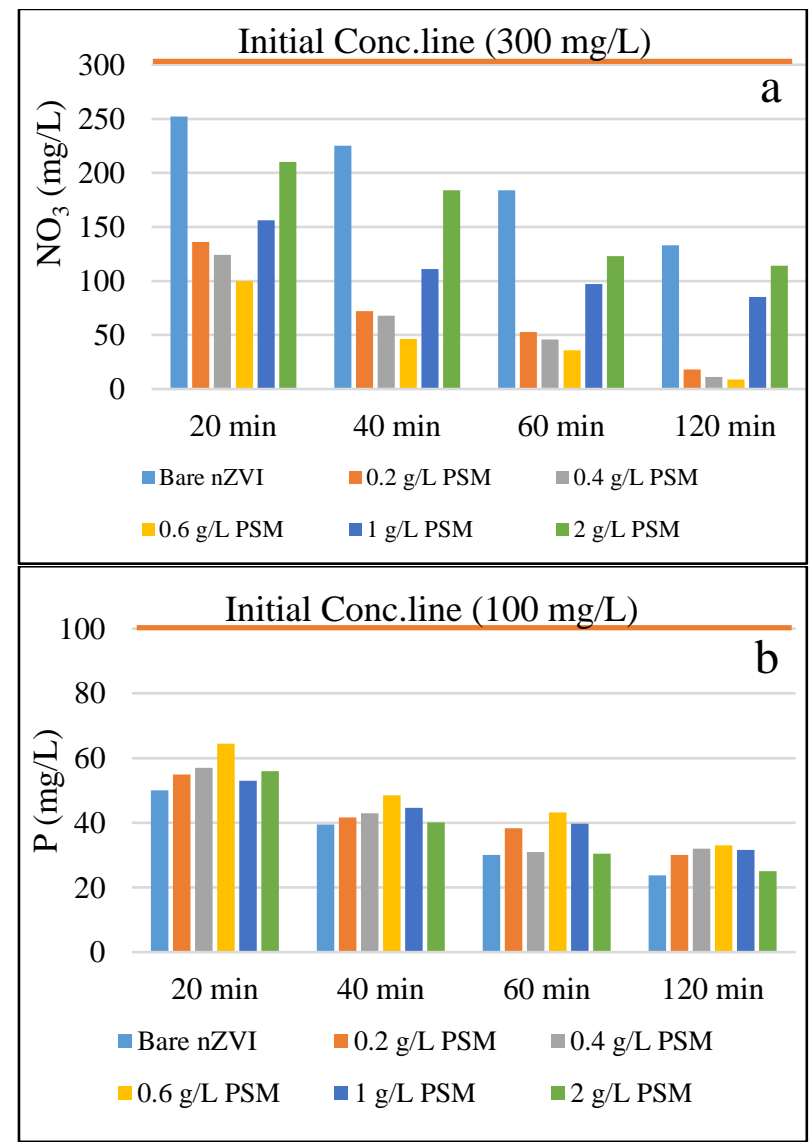

Fig. 4. Nitrate and phosphorus removal efficiency using bare and PSM-nZVI at different loading concentrations of PSM to nZVI varied from 0.2 to $2 \mathrm{~g} / \mathrm{L}$. Reaction conditions; $200 \mathrm{ml}$ of nitrate and phosphorus solution with an initial concentrations of 300 and $100 \mathrm{mg} / \mathrm{L}$ respectively. The reaction was conducted at room temperature for $2 \mathrm{hr}$. with a mixing speed of $1000 \mathrm{rpm}$ using a magnetic starrier.

3.3 Phosphorus removal using bare and PSM-nZVI Phosphorus removal using bare and PSM-nZVI was investigated. As shown in Fig. 4. b the addition of PSM to nZVI was not improved phosphorus uptake despite of using different concentrations of PSM. Phosphorus uptake remained better using bare nZVI. The maximum adsorption capacity of phosphorus was $61.04 \mathrm{mg} / \mathrm{g}$ using bare-nZVI, whereas, the maximum adsorption capacity of phosphorus decreased to $59.44 \mathrm{mg} / \mathrm{g}$ using PSMnZVI. The slight decrease in reactivity could be attributed to the effect of PSM on the adsorption of phosphorus on the surface of nZVI by blocking the reactive sites even at low concentrations of PSM.

\subsection{Effect of $\mathbf{p H}$ on phosphorus removal}

It has proved that in the previous reports nitrate and phosphorus removal favor acidic condition $[11,12]$. The effect of solution $\mathrm{pH}$ was investigated to detect the effect of $\mathrm{pH}$ on phosphorus removal using bare and PSM-nZVI. As a result, phosphorus removal significantly improved at the acidic conditions of $\mathrm{pH}$ whether using bare or emulsified nZVI as shown in Fig. 5. But there is a slight improvement in phosphorus removal using PSM-nZVI compared with bare-nZVI at different $\mathrm{pH}$. For instance, the maximum adsorption capacity of phosphorus reached $55.4 \mathrm{mg} / \mathrm{g}$ using bare $-\mathrm{nZVI}$ at $7 \mathrm{pH}$, but in the case of PSM-nZVI reached $64 \mathrm{mg} / \mathrm{g}$ at the same $\mathrm{pH}$. Further improvement of phosphorus removal by PSM-nZVI was observed at $\mathrm{pH} 9$ where the adsorption capacity of phosphors reached $60.32 \mathrm{mg} / \mathrm{g}$ but in case of bare-nZVI was only $39.2 \mathrm{mg} / \mathrm{g}$. The improvement of phosphorus removal using PSM-nZVI was also noted at $\mathrm{pH} 3$ and $\mathrm{pH}$ 12. This result suggested that the improvement of phosphorus removal using PSM-nZVI requires $\mathrm{pH}$ adjustment.

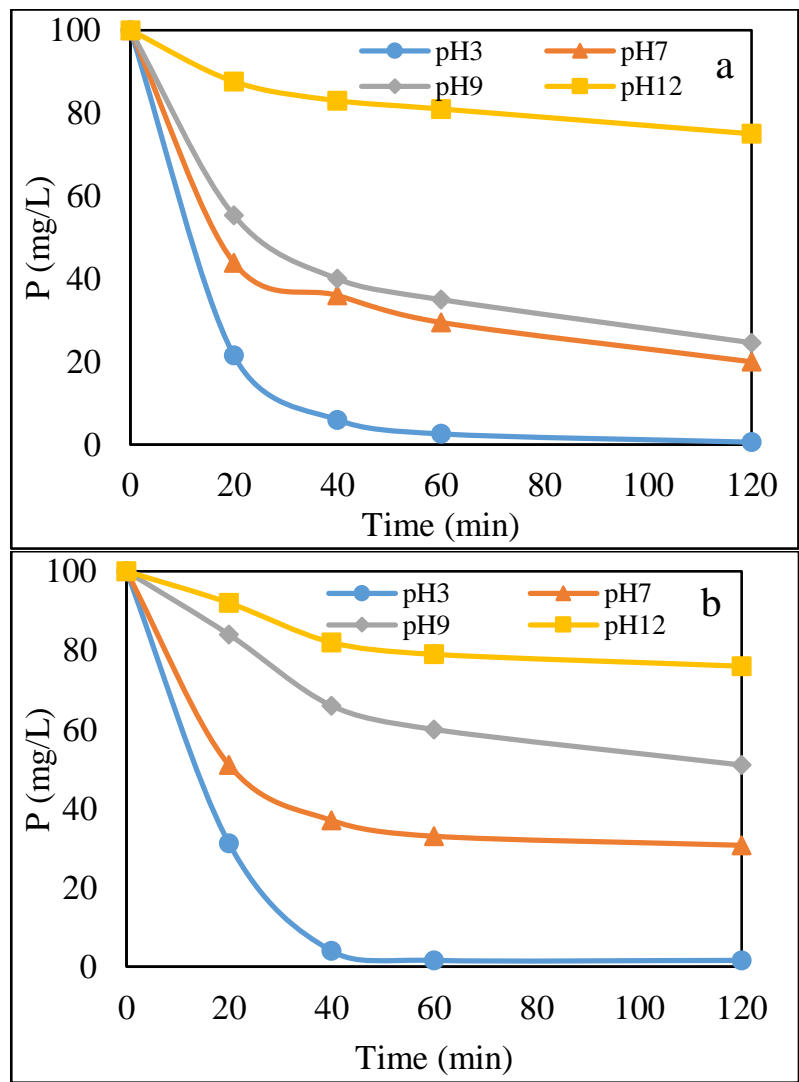

Fig. 5. effect of different $\mathrm{pH}$ values on phosphorus removal a) bare-nZVI; b) PSM-nZVI. 

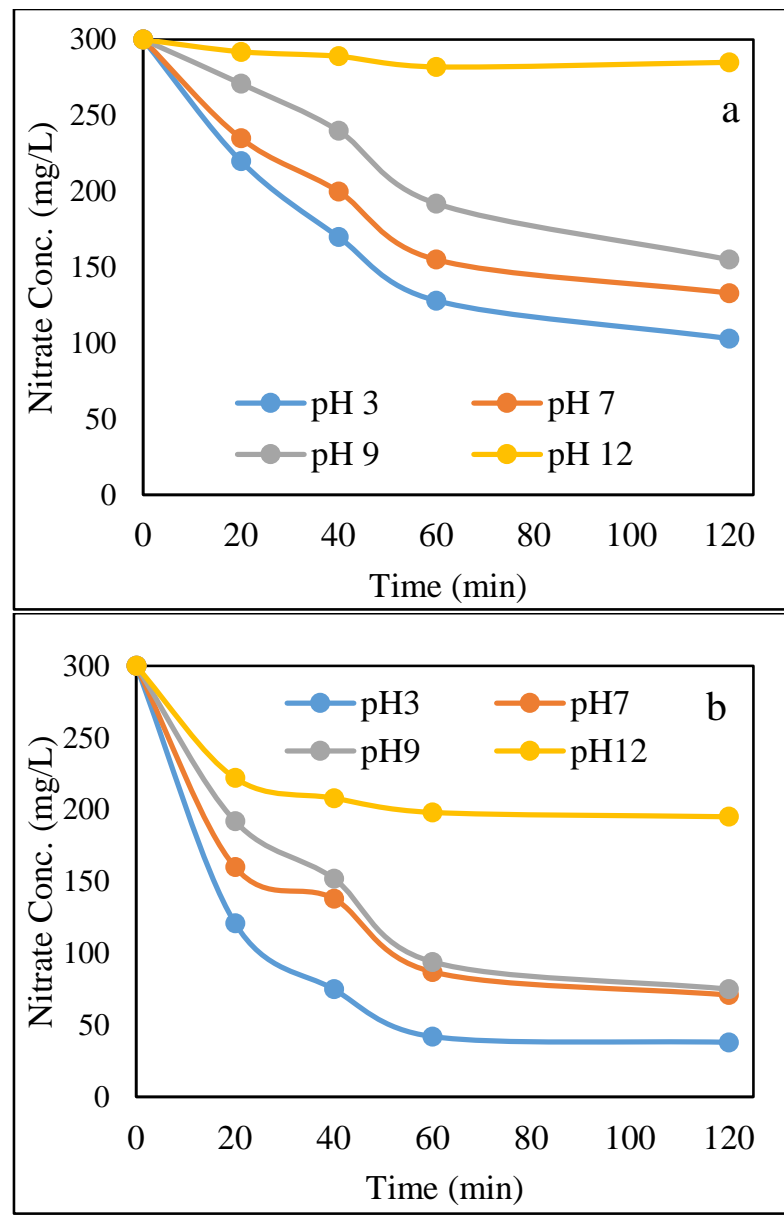

Fig. 6. effect of different $\mathrm{pH}$ values on nitrate removal a) bare-nZVI; b) PSM-nZVI.

\subsection{Effect of $\mathbf{p H}$ on Nitrate removal}

Fig. 6. shows the results of nitrate reduction using bare and emulsified nZVI at different $\mathrm{pH}$ values. The results showed that the reduction of nitrate either using bare or emulsified nZVI was favored at acidic and neutral $\mathrm{pH}$ vales. It was reported that the acidic solutions accelerate the corrosion reaction of nZVI, thereby increasing the released number of electron for further nitrate reduction [13]. Additionally, nitrate reduction significantly increased using the emulsified nZVI at different $\mathrm{pH}$ compared with bare nZVI at different $\mathrm{pH}$. These results confirmed the ability of the emulsified nZVI to be used for nitrate removal at a wide range of $\mathrm{pH}$ from 3 to 9 .

\subsection{Effect of adsorbate initial concentration}

\subsubsection{Effect of phosphorus initial concentration}

Several batch experiments were conducted to detect the effect of different phosphorus initial concentrations $(52.5,367.5,735$, and $1050 \mathrm{mg} / \mathrm{L})$ on it is removal efficiency using a fixed amount of adsorbent $(1 \mathrm{~g} / \mathrm{L}$ of bare or emulsified nZVI). To reach the equilibrium concentration, the reaction was conducted for $3 \mathrm{hr}$. As a result of these investigations, the adsorption of phosphorus was dramatically increased with increasing phosphorus initial concertation as shown in Fig.7. This could be attributed to the availability of phosphorus atoms in the aqueous solution. Interestingly and unlike the presented results in Fig. 7. b, the removal efficiency of phosphorus was improved using the emulsified nZVI comparing to the removal efficiency of bare nZVI as shown in Fig. 5. a and b. This also could be ascribed to the availability of phosphorus in the aqueous solution.

\subsubsection{Effect of nitrate initial concentration}

Fig. 8 shows nitrate reduction under different initial concentration of nitrate $(100,500,700$, and $1000 \mathrm{mg} / \mathrm{L})$ using both bare and emulsified nZVI. Nitrate reduction largely increased with increasing it is initial concentration whether using bare or emulsified nZVI. When using $1000 \mathrm{mg} / \mathrm{L}$ as an initial concentration, nitrate reduction was two times higher than using $500 \mathrm{mg} / \mathrm{L}$ as an initial concentration. Moreover, the reduction of nitrate was higher using PSM-nZVI compared to barenZVI at different initial concentrations.

\subsubsection{Adsorption isotherm}

Batch test were conducted for $3 \mathrm{hr}$. to reach the equilibrium state of nitrate and phosphorus removal using bare and emulsified nZVI. The batch experiments were conducted using different initial concentration of phosphorus and nitrate. Fig. 9 and 10 present the isothermal results of phosphorus and nitrate adsorption, detecting the relationship between the equilibrium adsorption capacities of bare and emulsified nZVI and concentration of nitrate and phosphorus in aqueous solution at equilibrium. It was noticed that the performance of PSM-nZVI was higher than the barenZVI towards nitrate and phosphorus removal, as indicated by the maximum adsorption capacities of bare and emulsified nZVI. (calculated from batch test results). To elucidate further, two adsorption isotherm models were evaluated for best fit to the experimental data. These two models are Langmuir (2) and Freundlich (3) and the models are described by the following equations.

$$
q_{e}=\frac{q_{m} k_{l} c_{e}}{1+k_{l} c_{e}} \stackrel{\text { Linearized }}{\longrightarrow} \frac{c_{e}}{q_{e}}=\frac{c_{e}}{q_{m}}+\frac{1}{q_{m} k_{l}}
$$
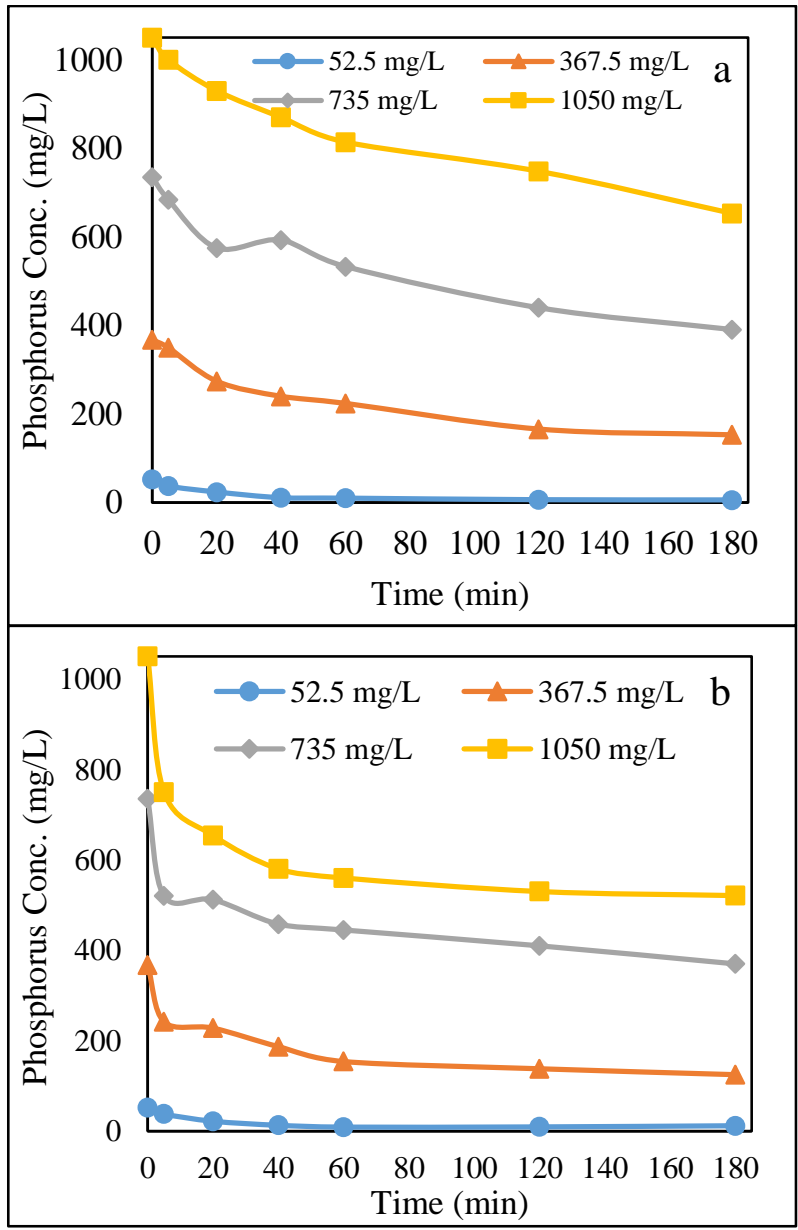

Fig.7. effect of phosphorus initial concentrations on it is removal efficiency using a) bare-nZVI, b) PSM-nZVI. 


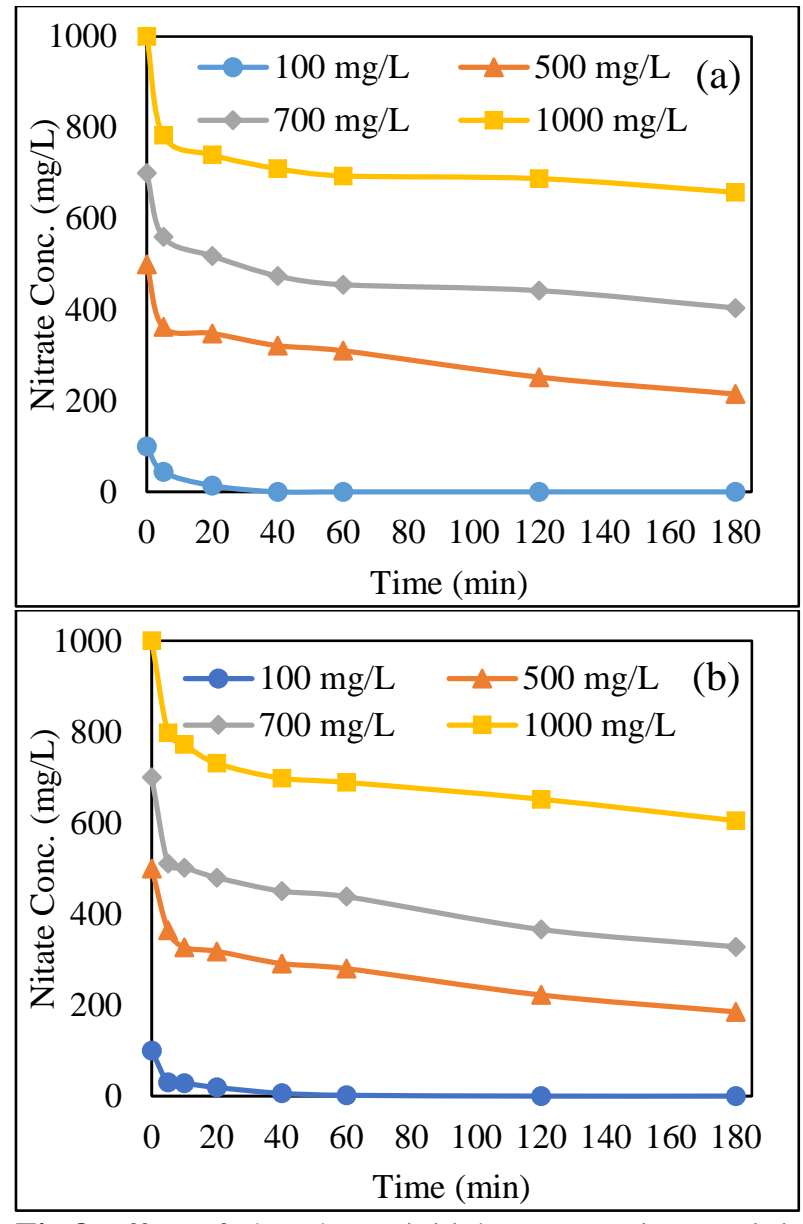

Fig.8. effect of phosphorus initial concentrations on it is removal efficiency using a) bare-nZVI, b) PSM-nZVI.

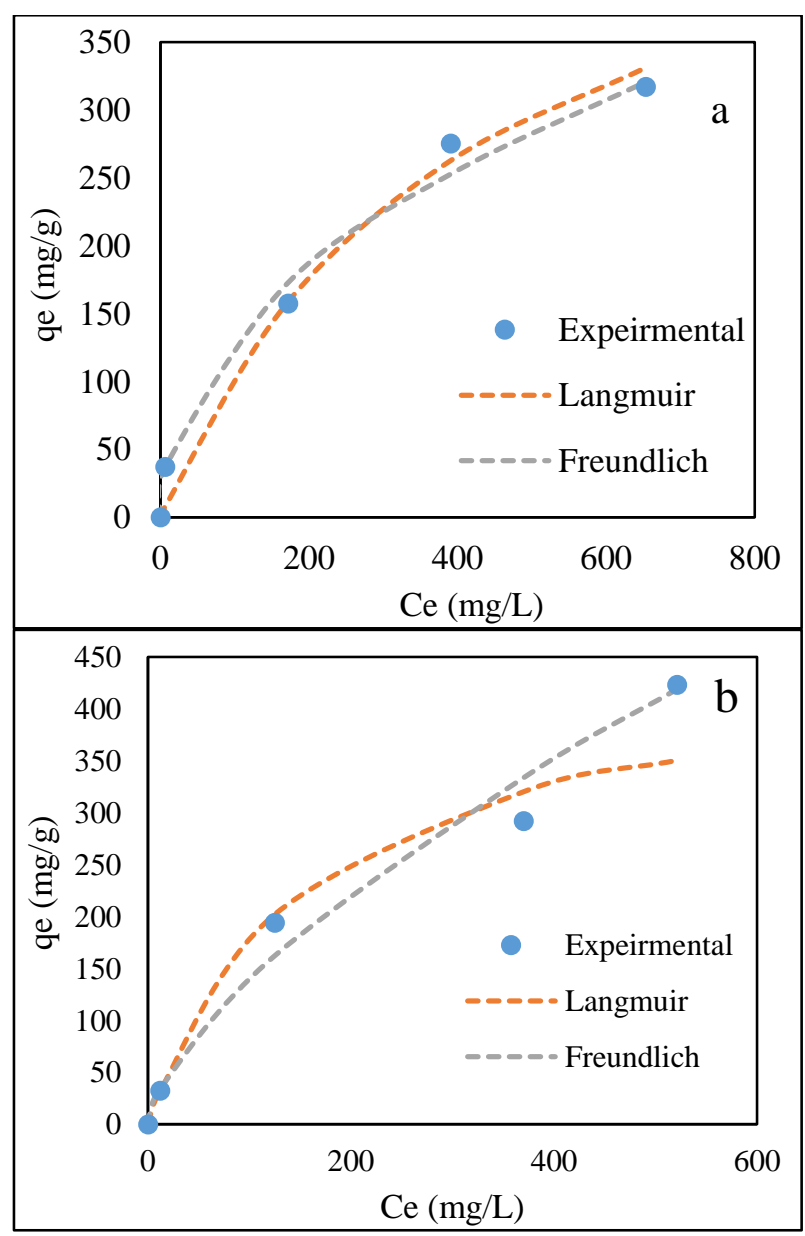

Fig. 9 adsorption isotherm of phosphorus onto a) barenZVI; b) PSM-nZVI.
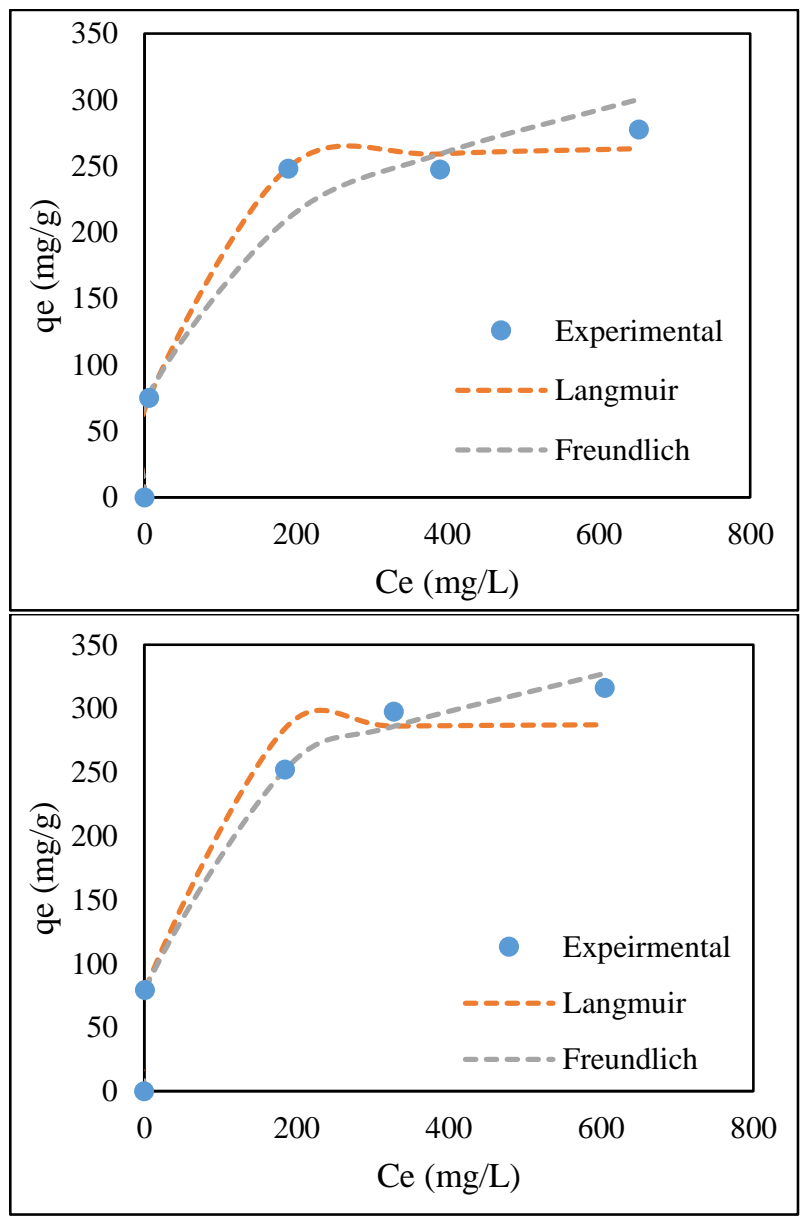

Fig. 10 adsorption isotherm of nitrate uptake using a) bare-nZVI, and b) PSM-nZVI

$q_{e}=k_{f} c_{e}^{\frac{1}{n} \stackrel{\text { Linearized }}{\longrightarrow}} \ln k q_{e}=\ln k_{f}+\frac{1}{n} \ln c_{e}$

The calculated parameters of these models are given in Table 1 and 2, including $\mathrm{q}_{\mathrm{m}}, \mathrm{k}_{\mathrm{L}}$ and $\mathrm{R}^{2}$ of Langmuir and $\mathrm{k}_{\mathrm{f}}, \mathrm{n}$, and $\mathrm{R}^{2}$ of Freundlich model. In terms of the best fit model criterion $\left(\mathrm{R}^{2}\right)$, the two models of Langmuir and Freundlich were competing and appropriate for describing the adsorption equilibrium data of nitrate and phosphorus either using bare or emulsified nZVI. However, Langmuir model was more appropriate in descripting the equilibrium data than Freundlich model, implying that the adsorption of nitrate and phosphorus is achieved on a monolayer sorption associated with uniform adsorption energies on the sorption sites.

\begin{tabular}{clcc} 
Model & Parameter & Phosphorus & Nitrate \\
\hline \multirow{4}{*}{ Langmuir } & $\mathrm{q}_{\mathrm{m}}(\mathrm{mg} / \mathrm{g})$ & 540 & 269.3 \\
& $\mathrm{~K}_{\mathrm{L}}(\mathrm{L} / \mathrm{mg})$ & 0.00242 & 0.0645 \\
\cline { 2 - 4 } & $\mathrm{K}_{\mathrm{f}}(\mathrm{mg} / \mathrm{g})$ & 15.96 & 46.6 \\
Freundlich & $\mathrm{n}$ & 2.1 & 3.48 \\
& $\mathrm{R}^{2}$ & 0.99 & 0.968 \\
\hline \hline
\end{tabular}

$\overline{\text { Table 1. isotherm parameters for nitrate and phosphorus }}$ adsorption by nZVI. 


\begin{tabular}{clcc} 
Model & Parameter & Phosphorus & Nitrate \\
\hline \multirow{2}{*}{ Langmuir } & $\mathrm{q}_{\mathrm{m}}(\mathrm{mg} / \mathrm{g})$ & 456 & 288.4 \\
& $\mathrm{~K}_{\mathrm{L}}(\mathrm{L} / \mathrm{mg})$ & 0.0063 & 0.378 \\
& $\mathrm{R}^{2}$ & 0.99 & 0.99 \\
\cline { 2 - 4 } Freundlich & $\mathrm{K}_{\mathrm{f}}(\mathrm{mg} / \mathrm{g})$ & 6.5 & 79.4 \\
& $\mathrm{n}$ & 1.506 & 4.524 \\
& $\mathrm{R}^{2}$ & 98 & 0.99 \\
\hline
\end{tabular}

$\overline{\overline{\text { Table 2. }} \text { isotherm parameters for nitrate and phosphorus }}$ adsorption by PSM-nZVI.

\section{CONCLUSIONS}

Nitrate and phosphorus removal using bare and PSMnZVI were investigated. Impregnation of nZVI with PSM as an emulsifier prevented the particles aggregations. Nitrate reduction was significantly improved using PSMnZVI where the maximum uptake capacity of nitrate reached $233.04 \mathrm{mg} / \mathrm{g}$ using PSM-nZVI and was only $133.6 \mathrm{mg} / \mathrm{g}$ using bare-nZVI. Phosphorus adsorption was not improved using PSM-nZVI.

\section{REFERENCES}

[1] A.I. Al-Zarah, Assessment of Trace Elements in Wastewater Effluent in Al-Hassa Eastern Province of the Kingdom of Saudi Arabia, Research Journal of Environmental Sciences 8 (2014) 405-421.

[2] O. Eljamal, J. Okawauchi, K. Hiramatsu, Removal of phosphorus from water using marble dust as sorbent material, Journal of Environmental Protection 3 (2012) 709.

[3] I. Maamoun, O. Eljamal, A.M. Khalil, Y. Sugihara, N. Matsunaga, Phosphate removal through nano-zero-valent iron permeable reactive barrier; column experiment and reactive solute transport modeling, Transport in Porous Media 125 (2018) 395-412.

[4] G. Lee, S. Modarresi, M.M. Benjamin, Efficient phosphorus removal from MBR effluent with heated aluminum oxide particles (HAOPs), Water research 159 (2019) 274-282.

[5] S. Takami, O. Eljamal, A.M. Khalil, R. Eljamal, N. Matsunaga, Development of continuous system based on nanoscale zero valent iron particles for phosphorus removal, Journal of JSCE 7 (2019) 30-42.

[6] L. El Hanache, L. Sundermann, B. Lebeau, J. Toufaily, T. Hamieh, T.J. Daou, Surfactant-modified MFI-type nanozeolites: Super-adsorbents for nitrate removal from contaminated water, Microporous and Mesoporous Materials 283 (2019) 1-13.

[7] M.A. Tofighy, T. Mohammadi, Nitrate removal from water using functionalized carbon nanotube sheets, Chemical Engineering Research and Design 90 (2012) 1815-1822.

[8] E. Eroglu, V. Agarwal, M. Bradshaw, X. Chen, S.M. Smith, C.L. Raston, K.S. Iyer, Nitrate removal from liquid effluents using microalgae immobilized on chitosan nanofiber mats, Green Chemistry 14 (2012) 2682-2685.

[9] R. Eljamal, I. Kahraman, O. Eljamal, I.P. Thompson, I. Maamoun, G. Yilmaz, Impact of nZVI on the formation of aerobic granules, bacterial growth and nutrient removal using aerobic sequencing batch reactor, Environmental Technology \& Innovation (2020) 100911.

[10] R. Eljamal, O. Eljamal, A.M. Khalil, B.B. Saha, N. Matsunaga, Improvement of the chemical synthesis efficiency of nano-scale zero-valent iron particles, Journal of environmental chemical engineering 6 (2018) 4727 4735 .

[11] O. Eljamal, A. Khalil, N. Matsunaga, Experimental and modeling column study of phosphorus removal by permeable reactive materials, Int J Environ Agric Res 3 (2017) 62-70.

[12] O. Eljamal, R. Mokete, N. Matsunaga, Y. Sugihara, Chemical pathways of nanoscale zero-valent iron (NZVI) during its transformation in aqueous solutions, Journal of environmental chemical engineering 6 (2018) 6207-6220.

[13] R. Eljamal, O. Eljamal, I. Maamoun, G. Yilmaz, Y. Sugihara, Enhancing the characteristics and reactivity of nZVI: Polymers effect and mechanisms, Journal of Molecular Liquids 315 (2020) 113714 